\title{
Soil moisture estimation from inverse modeling using multiple criteria functions
}

\author{
Sujittra Charoenhirunyingyos ${ }^{\mathrm{a}, *}$, Kiyoshi Honda ${ }^{\mathrm{a}}$, Daroonwan Kamthonkiat ${ }^{\mathrm{b}}$, Amor V.M. Ines ${ }^{\mathrm{c}}$ \\ a School of Engineering and Technology, Remote Sensing and Geographic Information Systems, Asian Institute of Technology, Bangkok, Thailand \\ ${ }^{\mathrm{b}}$ Department of Geography, Faculty of Liberal Arts, Thammasat University, Bangkok, Thailand \\ ${ }^{c}$ International Research Institute for Climate and Society, The Earth Institute at Columbia University, Palisades, NY, USA
}

\section{A R T I C L E I N F O}

\section{Article history:}

Received 9 April 2010

Received in revised form 3 December 2010

Accepted 7 December 2010

\section{Keywords:}

Soil moisture

Soil hydraulic parameters

Inverse modeling

Remote sensing

Optimization

\begin{abstract}
A B S T R A C T
Soil hydraulic parameters are essential inputs to agricultural and hydrologic models for simulating soil moisture. These parameters however are difficult to obtain especially when the application is aimed at the regional scale. Laboratory and field methods have been used for quantifying soil hydraulic parameters but they are proved to be laborious and expensive. An emerging alternative of estimating soil hydraulic parameters is soil moisture model inversion using remote sensing (RS) data. Although soil hydraulic parameters could not be derived directly from remote sensing, they could be quantified by the inverse modeling of RS data. In this study, we conducted a multi-criteria inverse modeling approach to estimate the rootzone soil hydraulic parameters in a rainfed rice field at depths $3,12,28$ and $60 \mathrm{~cm}$, respectively. The conditioning data used in the inverse modeling are leaf area index (LAI) and actual evapotranspiration $\left(\mathrm{ET}_{\mathrm{a}}\right)$ from satellite imageries, and soil moisture (SM) data from in situ measurements. The performances of all the model inversion experiments were evaluated against observed soil moisture in the field, and measured LAI during the growing season. The results showed that using remotely sensed LAI and $\mathrm{ET}_{\mathrm{a}}$ in the inverse modeling provided a good matching between observed and simulated soil moisture down to $28 \mathrm{~cm}$ depth from the soil surface. With the addition of soil moisture information from the site, the model inversion significantly improved the soil moisture simulation up to a depth of $60 \mathrm{~cm}$.
\end{abstract}

(c) 2010 Elsevier B.V. All rights reserved.

\section{Introduction}

Accurate knowledge of the state of soil moisture (spatial and temporal) is essential for a wide range of applications in agriculture and water management. Rootzone soil moisture can be used as an index in early warning systems (for flood or drought), and in the prediction of crop yields. But despite this importance, rootzone soil moisture is not always available for immediate applications in the field. Recent advances in remote sensing (microwave) allowed the measurements of soil moisture at a few centimeters from the soil surface (Jackson et al., 1995; Njoku et al., 2003). Although microwave remote sensing overcomes the interference of clouds, the resulting soil moisture data are still at low spatial resolution $(25-60 \mathrm{~km})$ and particularly limiting when applied in areas with high surface roughness and lush vegetations (Srivastava et al., 2003). To improve the utility of such soil moisture data, they have to be downscaled at the appropriate resolution and translated into soil moisture at deeper depths.

An emerging approach to estimate rootzone soil moisture is by integrating moderate to higher resolution remote sensing data e.g., vegetation indices with a Soil-Vegetation-Atmosphere-Transfer

\footnotetext{
* Corresponding author.

E-mail address: sujittra_geo@hotmail.com (S. Charoenhirunyingyos).
}

(SVAT) model using inverse modeling (e.g., Ines et al., 2006; Olioso et al., 2005). Soil moisture models require input parameters that describe vegetation and soil properties for simulating soil moisture, and inverse modeling can be used to incorporate measured data (remotely sensed or in situ) into the dynamic model to estimate these input parameters, e.g., soil hydraulic parameters, which in turn be used to simulate rootzone soil moisture in forward modeling.

A number of studies have been made to estimate soil parameters using remote sensing to simulate soil moisture (Ragab, 1995; Walker et al., 2001a,b). Several studies optimized soil parameters using soil moisture and soil temperature information (Enthekabi et al., 1994; Gupta et al., 1999; Hogue et al., 2005; Liu et al., 2005). Feddes et al. (1993a,b) used evapotranspiration (ET) and surface soil moisture to derive effective soil hydraulic parameters of the rootzone in a hypothetical watershed. Jhorar et al. (2002, 2004) also used evapotranspiration to inversely identify effective soil hydraulic parameters in a hypothetical soil profile. Ines and Mohanty (2008) used near-surface soil moisture from field measurements for quantifying effective soil hydraulic parameters of the rootzone. It is evident that information contents from soil moisture and evapotranspiration can be exploited to infer on soil hydraulic properties indirectly.

In this study, we conducted an inverse modeling experiments to estimate soil hydraulic parameters in a rainfed rice field in Ubon 


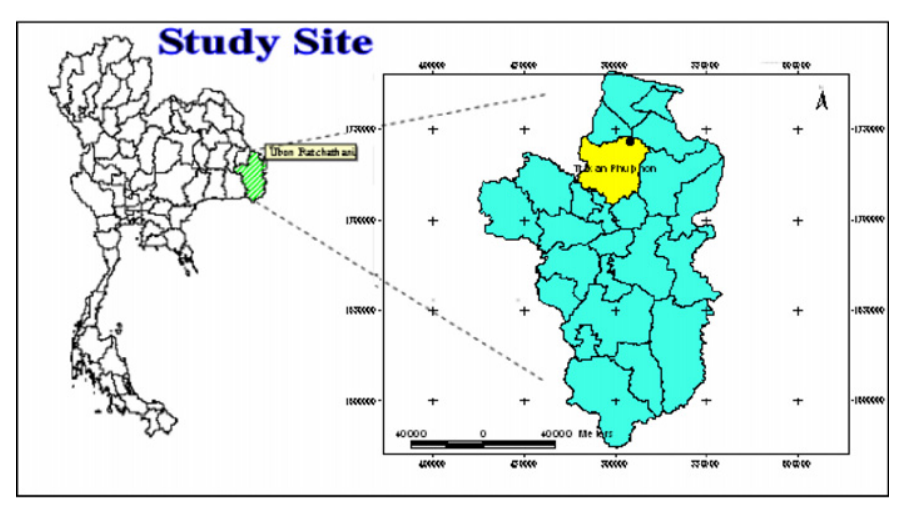

Fig. 1. Study site in Trakan Phutphon district, Ubon Ratchathani Province, Thailand.

Ratchathani, Thailand using remotely sensed data, actual evapotranspiration $\left(\mathrm{ET}_{\mathrm{a}}\right)$ and leaf are index (LAI), and observed soil moisture (SM) in the field employing a multi-objective optimization.

\section{Materials and methods}

\subsection{Study area and instrumentation}

The study site is located in Trakan Phutphon District $\left(15^{\circ} 42^{\prime} 22^{\prime \prime} \mathrm{N} 105^{\circ} 00^{\prime} 21^{\prime \prime} \mathrm{E}\right)$ in the upper part of Ubon Ratchathani Province in Northeastern Thailand (Fig. 1). Most of the farmers in the study site grow rice at one cropping per year because their rice fields are mostly rainfed. The cropping cycle starts at the beginning of the rainy season from late April to late May. One month later, rice seedlings are transplanted in the flooded fields at around late
June. Rice from the paddy fields is usually harvested after the rainy season around late October to mid November.

A near real-time weather and flux observation station (Fig. 2) was set up in the paddy field with the support of the Thailand Research Fund (TRF). Data were collected from the station during the whole cropping season starting from the dry season in March 2007, when the field was bare and sparsely covered with grass. The harvesting period in the study area is around mid-November. After the rice growing season, the farmers let their fields fallow until rains start again from late May to June. The instruments used at the meteorological stations are shown in Fig. 2.

The sensors comprise of Davis General Weather Station (symbol 1) installed at $2 \mathrm{~m}$ above ground for recording temperature, humidity, rainfall, wind speed and solar radiation, and two Bowen ratio instruments (symbol 2) mounted at heights of 2 and $10 \mathrm{~m}$. These Bowen instruments measure temperature and vapor pressure variations at 2 and $10 \mathrm{~m}$ above ground necessary to calculate the actual evapotranspiration $\left(\mathrm{ET}_{\mathrm{a}}\right)$. The data from the different sensors are stored in a database, which can be accessed remotely through the Internet using a satellite link (receiver) installed in the site (symbol 3 ). The Internet service was provided by IPStar. Other sensors in the station include a Net Radiometer (symbol 4) set up at $2.5 \mathrm{~m}$ above ground for recording net radiation. Apart from the Davis instruments, there are other sets of wind speed sensors and rain counters (symbol 5) installed at $2 \mathrm{~m}$ and $10 \mathrm{~m}$ heights. The Sensor Control box that controls the whole system consists of a Linux Box (computer server) and Data Acquisition System (DAQs) from National Instruments (NI) set up to record the data (symbol 6). Underground soil moisture sensors have also been installed at 3 , 12,28 and $60 \mathrm{~cm}$ soil (symbol 7), these sensors measure the dielectric constant or permittivity by finding the rate of change of voltage in the soil, which can be translated to volumetric soil moisture contents.

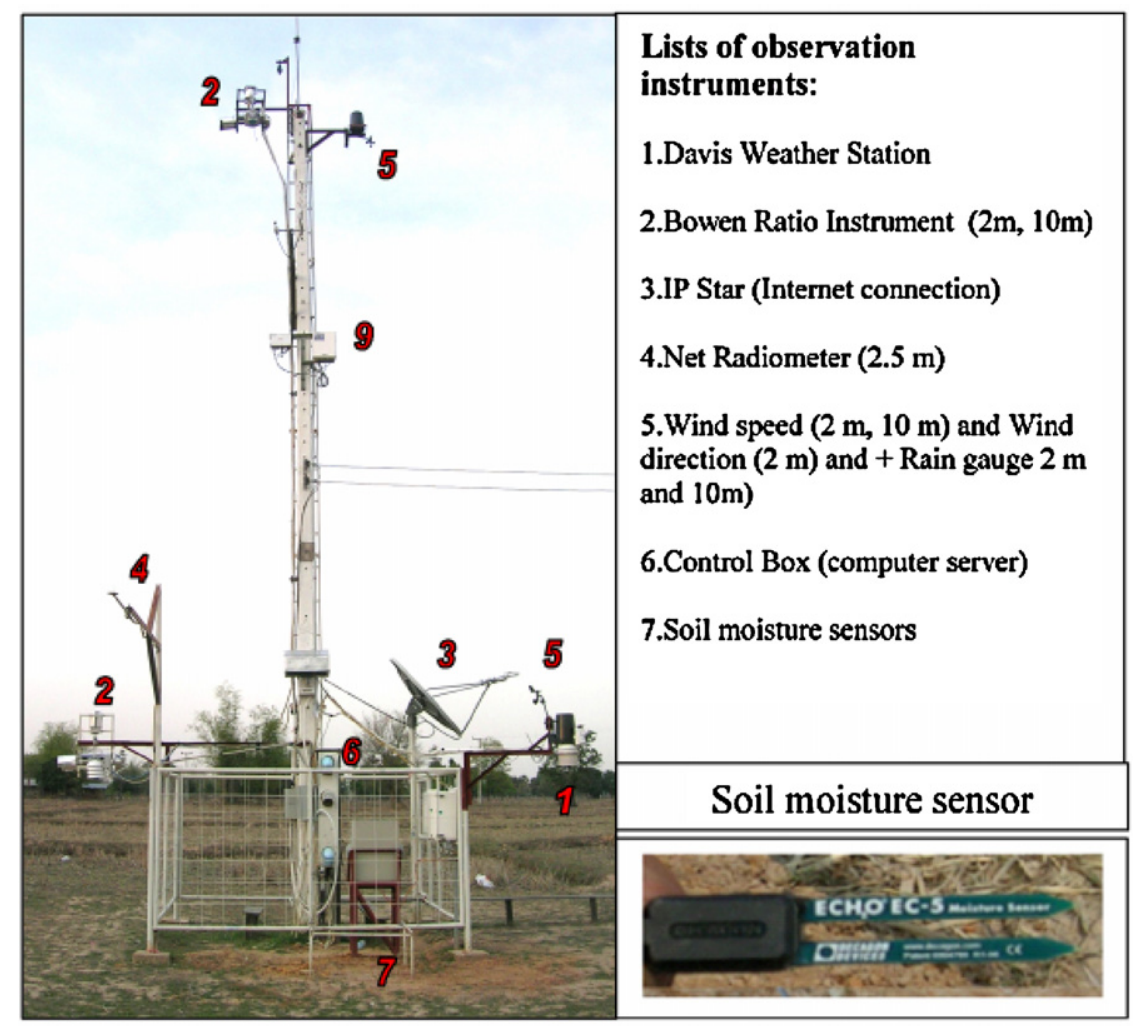

Fig. 2. Observation system. 


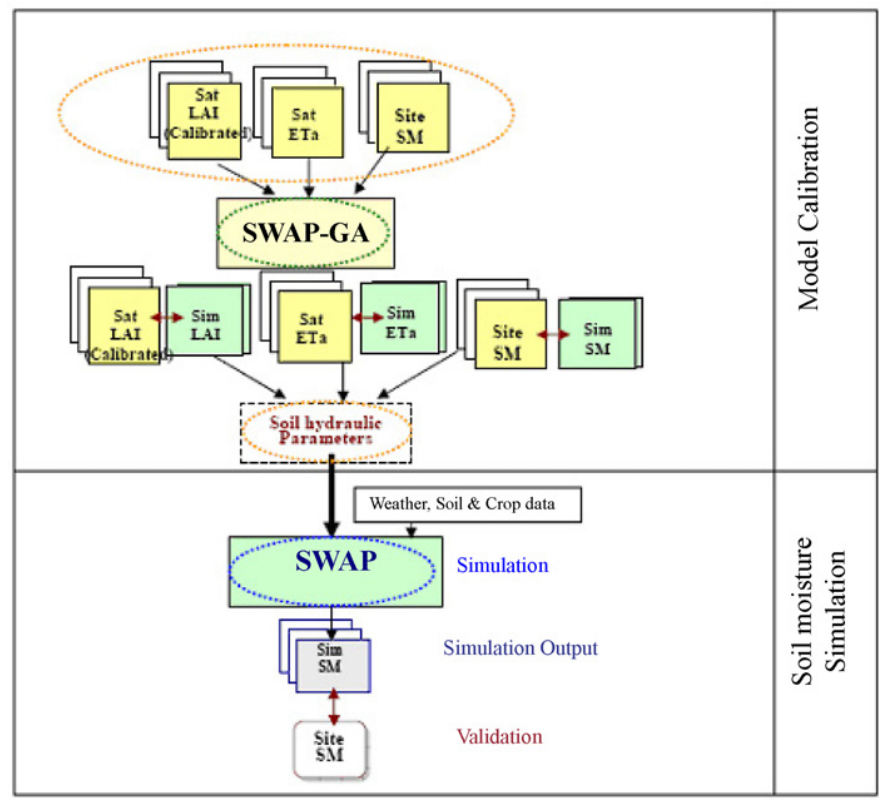

Fig. 3. Framework of study.

\subsection{Soil-Water-Atmosphere-Plant and Genetic Algorithm (SWAP-GA): model inversion framework}

Fig. 3 shows the inverse modeling framework used in this study. The inverse modeling was used to estimate five Mualem-van Genuchten soil hydraulic parameters (shape parameters $\alpha$ and $n$, saturated and residual soil moisture contents $\theta_{\text {sat }}$ and $\theta_{\text {res }}$, and saturated hydraulic conductivity, $K_{\text {sat }}$ ) for each considered soil layer simultaneously, a total of 20 soil hydraulic parameters estimated at once. In this study, actual evapotranspiration $\left(E_{a}\right)$, leaf are index (LAI) from remote sensing and profile soil moisture (SM) from site were used as conditioning data for the inverse modeling. Soil moisture was also used as conditioning data in combination with $\mathrm{ET}_{\mathrm{a}}$ and LAI to evaluate how soil hydraulic parameters could be identified and seen improvements in soil moisture simulation. Ines and Droogers $(2002 a, b)$ observed that profile soil moisture is a more effective search criterion for inverse modeling because the soil hydraulic parameters are directly related to soil moisture dynamics, therefore we also explored it here. Field scale soil moisture monitoring is usually easier perform, and the cost of sensors is not expensive, thus offer an alternative for estimating landscape soil hydraulic properties by employing inverse modeling than by expensive soil hydraulic testing using laboratory method.

SWAP-GA is a combined Soil-Water-Atmosphere-Plant (SWAP) model and Genetic Algorithm (GA) (Ines and Droogers, 2002a,b; Ines et al., 2006). SWAP constitutes the forward model, while GA searches for the unknown model parameters using the information contents of the (time series of) conditional data (e.g., $\mathrm{ET}_{\mathrm{a}}$, LAI and soil moisture) by matching these values with the simulated ones by the forward model. Brief descriptions of SWAP and GA are as follows.

The SWAP model is a physically based agro-hydrological model used to simulate the relationship of the soil, water, atmosphere and plants (van Dam, 2000). The first version of SWAP, called SWATRE was developed more than 30 years ago (Feddes et al., 1978). This model was successful in studying the soil, water, atmosphere, and plant relationships in many parts of the world that resulted in increased flexibility of studying the soil moisture dynamics in different climatic conditions. The model uses the Richards' equation to simulate vertical soil water movement. The soil hydraulic func- tions in the model is defined by the Mualem-van Genuchten (MVG) equations (Mualem, 1976; van Genuchten, 1980) that describe the capacity of the soil to store, release and transmit water under different environmental and boundary conditions (Eqs. (1) and (2)):

$S_{e}=\frac{\theta(h)-\theta_{\text {res }}}{\theta_{\text {sat }}-\theta_{\text {res }}}=\left[\frac{1}{1+|\alpha h|^{n}}\right]^{m}$

$K(h)=K_{\mathrm{sat}} S_{e}^{\lambda}\left[1-\left(1-S_{e}^{1 / m}\right)^{m}\right]^{2}$

where $S_{\mathrm{e}}$ is the relative saturation; $\theta_{\text {res }}$ and $\theta_{\text {sat }}$ are the residual and saturated soil water contents $\left(\mathrm{cm}^{3} \mathrm{~cm}^{-3}\right) ; \alpha\left(\mathrm{cm}^{-1}\right) ; n, m$ and $\lambda$ are shape parameters of the retention and the conductivity functions; $K_{\text {sat }}$ is the saturated hydraulic conductivity $\left(\mathrm{cm} \mathrm{d}^{-1}\right)$, and $m=1-1 / n$. The values of these parameters are distinct among soil (textural) types and have to be defined as inputs for the simulation model. Potential evapotranspiration $\left(\mathrm{ET}_{\mathrm{p}}\right)$ in the SWAP model is calculated using the Penman-Monteith equation while actual evapotranspriation $\left(\mathrm{ET}_{\mathrm{a}}\right)$ is calculated by using the root water uptake reduction due to water and/or salinity stress. The potential root water extraction rate, integrated over the rooting depth, is equal to the potential transpiration rate $\left(T_{\text {pot }}\right)$, which is governed by atmospheric conditions. Water stress in SWAP is described by the function proposed by Feddes et al. (1978) and salinity stress by the response function of Mass and Hoffman (1977). The parameterization of water and salinity stresses is considered as multiplicative. To simulate crop growth, SWAP uses the World Food Studies (WOFOST) model (Supit et al., 1994). WOFOST simulates the grain yields from biomass accumulation until the anthesis (flowering) and during grain filling. Calculated on a daily basis, Leaf Area Index (LAI) is determined by the fraction of carbon assimilates that partitioned into the leaves, as a result of photosynthetic activity (van Dam, 2000). In this study, the detailed crop model WOFOST was used in the simulations of crop growth so that LAI can be modeled dynamically, and matched with the MODIS-derived LAI.

Holland (1975) first introduced Genetic Algorithms (GAs), a mathematical model of natural genetics, where the mechanics of nature have been abstracted to be used in search and optimization problems. GA is different from other optimization techniques in a number of significant ways. GA consists of three basic operators, namely: (i) selection, (ii) crossover and (iii) mutation. These three processes are repeated for many generations to produce the best chromosomes that can represent the optimal solution to the problem (Goldberg, 1989). In this case, the unknown model parameters are represented as chromosomes (combinations of $\alpha, n, \theta_{\text {sat }}, \theta_{\text {res, }}$, $K_{\text {sat }}$ in binary form) that undergo selection, crossover and mutation (see Ines and Droogers, 2002a,b). The GA used in this study is the modified-microGA, a variant of GA that uses a restarting small population, creep mutation (i.e., mutation at the base 10 values) and an intermittent jump mutation (i.e., mutation at the (binary) base 2 values) as a function of number of generations (Carroll, 1998; Ines and Droogers, 2002a,b; Ines and Mohanty, 2008).

\subsection{Data}

The datasets used in this study comprise the input data of the forward model(SWAP), e.g., weather, crop and soils, and the inverse model SWAP-GA conditioning datasets namely, remotely sensed $\mathrm{ET}_{\mathrm{a}}$, LAI and field scale soil moisture.

\subsubsection{Satellite imageries}

Moderate Resolution Imaging Spectroradiometer (MODIS) was chosen for this study because of its high temporal resolution and free access in the Internet. MODIS can also provide data in $36 \mathrm{spec}-$ tral bands as well as data of various products such as leaf area 


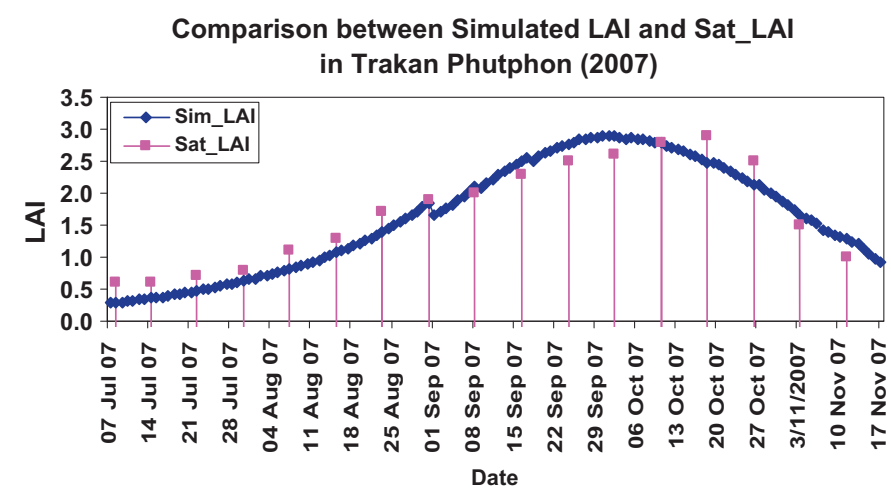

Fig. 4. Comparison between simulated LAI and Satellite LAI in SWAP-GA model using LAI information (Charoenhirunyingyos et al., 2010).

index, surface reflectance, surface temperature and surface emissivity, which are required in the calculation of surface fluxes (e.g., $\mathrm{ET}_{\mathrm{a}}$ ) used in the inverse modeling. The following are the main RS products used in this study.

2.3.1.1. Leaf area index (LAI). We used MODIS 8-day composite product (MOD15A2) with spatial resolution of $1 \mathrm{~km}$ for extracting RS-based LAI. The LAI derived from MODIS was slightly lower than the Site-LAI because of spatial resolution difference in the LAI measurements. Since the output of SWAP is representative of a homogenous field, the calibration of MODIS LAI to field level becomes necessary. In this study, MODIS LAI was calibrated using Eq. (3) obtained from calibrating the MODIS LAI with LAI determined by a hand-held LAI meter. The calibrated MODIS LAI was used in the inverse modeling (Fig. 4).

Site_LAI $=1.2384$ Sat_LAI +0.1859

2.3.1.2. Actual evaportranspiration $\left(E T_{a}\right)$. Actual evaportranspiration $\left(\mathrm{ET}_{\mathrm{a}}\right.$ ) from remote sensing (RS) was estimated from MODIS images using Surface Energy Balance Algorithm for Land (SEBAL) (Bastiaanssen et al., 1998). SEBAL is a physically based, analytical image processing method used to determine $\mathrm{ET}_{\mathrm{a}}$ based on residual energy balance approach (Hong et al., 2009). Various applications have demonstrated the ability of SEBAL to accurately estimate daily evapotranspiration. SEBAL requires visible, near-infrared and thermal infrared satellite imageries together with routine weather data (Mutiga et al., 2010) to estimate the sensible heat flux. Knowing the incident solar radiation, ground and sensible heat flux allows the estimation of the latent heat flux, which can be translated into $\mathrm{ET}_{\mathrm{a}}$ values (Bastiaanssen et al., 1998).

This study used MODIS daily surface reflectance products $500 \mathrm{~m}$ (MOD09GA) to retrieve the NDVI and surface albedo. MODIS daily land surface temperature and emissivity products at $1 \mathrm{~km}$ (MOD11A1) were used to retrieve the surface temperature and emissivity. All images were all harmonized into $500 \mathrm{~m}$ resolution. However, only cloud free satellite data was used to determine the $\mathrm{ET}_{\mathrm{a}}$. Only 45 images obtained in 1 year (2007) could be considered of good quality. The SEBAL derived $\mathrm{ET}_{\mathrm{a}}$ was compared with $\mathrm{ET}_{\mathrm{a}}$ measured in the field using the Bowen ratio method. Although similar trend was obtained, the $\mathrm{ET}_{\mathrm{a}}$ from ground measurement showed higher values than the values using satellite which could be due to the scale difference of the measurements. Scaling the $\mathrm{ET}_{\mathrm{a}}$ using linear scaling or by selecting better spatial resolution of the satellite image such as ASTER could improve the mismatch scale of the data. Scaling $\mathrm{ET}_{\mathrm{a}}$ was not done in this study as it was assumed that the moderate resolution (MODIS) data could serve as representative of the study area. At the beginning of the cropping season (2nd week of July) Bowen-ET $\mathrm{a}_{\mathrm{a}}$ was $0.6-0.7 \mathrm{~cm} \mathrm{~d}^{-1}$ while the Sat-ET $\mathrm{a}$ was
Table 1

Soil texture analysis of Trakan Phutphon rice field.

\begin{tabular}{llllll}
\hline Layer & Sand & \% Silt & \% Clay & Texture & \% Organic matter \\
\hline $3 \mathrm{~cm}$ & 39 & 49 & 12 & Loam & 1.14 \\
$12 \mathrm{~cm}$ & 32 & 44 & 24 & Loam & 0.93 \\
$28 \mathrm{~cm}$ & 32 & 36 & 32 & Clay loam & 0.66 \\
$60 \mathrm{~cm}$ & 16 & 31 & 53 & Clay & 0.31 \\
\hline
\end{tabular}

$0.3-0.4 \mathrm{~cm} \mathrm{~d}^{-1}$. The high values of $\mathrm{ET}_{\mathrm{a}}$ are the result of flooding condition in the field. After harvesting (3rd week of November), the Bowen-ET $\mathrm{E}_{\mathrm{a}}$ was about $0.3-0.5 \mathrm{~cm} \mathrm{~d}^{-1}$ while the Sat-ET $\mathrm{a}$ value was $0.1-0.2 \mathrm{~cm} \mathrm{~d}^{-1}$.

\subsubsection{Ancillary data}

2.3.2.1. Weather. Weather data were obtained from the weather station located in the paddy field during the study period. When data are not available due to maintenance activities, we used data from nearby Thai Meteorological Department (TMD) agro meteorological station in Ubon Ratchathani Province. Weather data are necessary as inputs to the SWAP model. Such data include the daily average minimum and maximum temperatures $\left({ }^{\circ} \mathrm{C}\right)$, humidity $(\mathrm{hPa})$, solar radiation $\left(\mathrm{kJ} \mathrm{m}^{-2}\right)$, wind speed $\left(\mathrm{m} \mathrm{s}^{-1}\right)$, and rainfall $(\mathrm{mm})$.

2.3.2.2. Soils. Soil texture and organic matter are required inputs for the SWAP model. Soil core samples were collected from the four observation depths $(3,12,28$ and $60 \mathrm{~cm})$ from the study site and analyzed at the Kasetsart University Laboratory in Bangkok, Thailand. The result of soil texture analysis showed the soil layers consist of loam, loam, clay loam and clay, respectively (Table 1).

2.3.2.3. Soil moisture. Soil moisture data was monitored from EC-5 soil moisture sensors (Decagon Devices Incorporation) which has an accuracy of VWC 3\% for different soil media. The sensors were also calibrated in the study site (Charoenhirunyingyos et al., 2010). EC-5 sensors measure the dielectric constant or permittivity of the material by finding the rate of change of voltage on a sensor that is embedded in the medium. These sensors were installed at 3,12, 28, and $60 \mathrm{~cm}$ depths below the soil surface. The depths of the sensors were chosen in order to cover the root zone area of the crop and the range of soil texture in the soil profile. The observed soil moisture at the site was used for inverse modeling and validation purposes.

2.3.2.4. Crops. Crop data were collected from the paddy starting from land preparation, transplanting, flowering, until the ripening stage of the rainfed rice. LAI was measured in the field one to two times per week using LAI meter (LAI-2000) from LI-COR Company. LAI meter is a tool used to measure LAI which directly affects the interception and absorption of light by the canopy. In this study, the LAI data was collected from 20 to 30 points near the weather station and then a representative average was taken on the day when measurements were taken. Crop information such as crop height was also measured in the field every week while the planting and harvesting dates were also recorded.

\subsection{Model inversion experiments}

The unknown parameters in the inverse modeling were the Mualem-van Genuchten soil hydraulic parameters of the four soil layers. The initial values of the unknown parameters were generated between the minimum and maximum values of the selected soil hydraulic parameters (Table 2). GA optimized these soil hydraulic parameters by matching the observed and simulated values by SWAP until the difference is minimized. The final parameter values are inputted to SWAP to simulate the soil moisture, the 
Table 2

Genetic algorithm parameters used in the inverse modeling.

\begin{tabular}{|c|c|c|c|c|}
\hline \multirow{2}{*}{$\begin{array}{l}\text { Soil hydraulic } \\
\text { parameters }\end{array}$} & \multicolumn{2}{|l|}{ Range } & \multirow{2}{*}{$\begin{array}{l}\text { Search } \\
\text { space }\end{array}$} & \multirow[t]{2}{*}{$2^{L}$} \\
\hline & Min & Max & & \\
\hline$\alpha\left(\mathrm{cm}^{-1}\right)$ & 0.006 & 0.033 & 32 & $2^{5}$ \\
\hline$n$ (unit less) & 1.2 & 1.61 & 64 & $2^{6}$ \\
\hline$\theta_{\text {res }}\left(\mathrm{cm}^{3} \mathrm{~cm}^{-3}\right)$ & 0.005 & 0.1 & 128 & $2^{7}$ \\
\hline$\theta_{\text {sat }}\left(\mathrm{cm}^{3} \mathrm{~cm}^{-3}\right)$ & 0.37 & $0.6^{\mathrm{a}}$ & 32 & $2^{5}$ \\
\hline$K_{\text {sat }}\left(\mathrm{cm} \mathrm{d}^{-1}\right)$ & 1.84 & 55.7 & 1024 & $2^{10}$ \\
\hline
\end{tabular}

Population size $=10$; Max. no. of generations $=50$; Prob. of crossover $=0.5$; Prob. of creep mutation $=0.8$; Prob. of jump mutation $=0.9$. $L$ - length of binary bits.

a 0.55 for 12 and $28 \mathrm{~cm}$ depths.

result of which was validated using the direct field observations from soil moisture sensors. The following shows the formalism used in the model inversion experiments.

The soil hydraulic parameters, for each layer were represented in the SWAP-GA as $p=\left\{\alpha, n, \theta_{r}, \theta_{s}, K_{s}, \lambda\right\}$. But since $\lambda$ can be estimated as 0.5 for most soils (Mualem, 1976) we can reduce the dimensionality of the inverse problem for each soil layer by $p_{i=1, m-1}=\left\{\alpha, n, \theta_{r}, \theta_{s}, K_{s}\right\}$, hence (for all layers) $k=\left\{P_{j, i=1, \mathrm{~m}-1}, \lambda_{j}\right\}$, where $j$ is an index of the soil layers, $i$ is the index for soil hydraulic parameter, $m$ is the maximum number of parameters, and $p$ corresponds to the set of soil hydraulic parameters. The inverse problem of the unsaturated flows in the root zone can be defined simply by estimating the soil hydraulic parameters k from the Richards' equation iteratively.

The fitness function is defined as:

$p^{\prime}=\left(\frac{1}{Z(k)}\right)$

where $Z$ is defined as the difference between the observed $\left(x_{i}\right)$ and simulated $\left(\hat{x}_{i}\right)$ soil moisture, ET or LAI:

$Z(k)=\frac{1}{N} \frac{1}{M} \sum_{t=1}^{N} \sum_{i=1}^{M}\left|x_{i}(k, t)-\hat{x}_{i}(t)\right|$

where $N$ is the number of observations, $M$ is the number of soil layers, $t$ and $i$ are the running indices for the number of observations and soil layers, respectively.

Multiple criteria functions were developed to solve the inverse problem (Eqs. (6)-(13)). The delta $(\Delta)$ terms, $\Delta \mathrm{SM}, \Delta \mathrm{ET}$, and $\Delta \mathrm{LAI}$, have been normalized based on the maximum and minimum observed values to be able include multiple variables of varying units in the functions:

$$
\begin{aligned}
\varepsilon_{1} \circ \Delta \mathrm{SM}+\varepsilon_{1} \circ \Delta \mathrm{ET}+\varepsilon_{1} \circ \Delta \mathrm{LAI} & \left(\varepsilon_{1}+\varepsilon_{2}+\varepsilon_{3}=1.0\right) \\
& \text { Range }=0 \leq \varepsilon \leq 1
\end{aligned}
$$

where $\varepsilon_{1}, \varepsilon_{2}, \varepsilon_{3}$ are the weighted coefficients for SM, ET a , and LAI, respectively. The sum of $\varepsilon_{1}, \varepsilon_{2}, \varepsilon_{3}$ must be equal to one. In order to evaluate the contributions of SM, ET a and LAI, $\varepsilon_{1}, \varepsilon_{2}, \varepsilon_{3}$ were set in several combinations as shown below:

Case I (SM):

Objective Function $=\frac{1}{N} \sum_{t=1}^{N}\left|\mathrm{SM}_{\mathrm{obs}, t}-\mathrm{SM}_{\mathrm{sim}, t}\right|$

Case II $\left(\mathrm{ET}_{\mathrm{a}}\right)$ :

Objective Function $=\frac{1}{N} \sum_{t=1}^{N}\left|\mathrm{ET}_{\mathrm{obs}, t}-\mathrm{ET}_{\text {sim }, t}\right|$
Case III (LAI):

Objective Function $=\frac{1}{N} \sum_{t=1}^{N}\left|\mathrm{LAI}_{\mathrm{obs}, t}-\mathrm{LAI}_{\mathrm{sim}, t}\right|$

Case IV (ET $\mathrm{a}_{\mathrm{a}}$ and LAI):

Objective Function $=\frac{I}{N} \sum_{t=1}^{N} \mid 0.5\left[\mathrm{LAI}_{\mathrm{obs}, t}-\mathrm{LAI}_{\mathrm{sim}, t}\right]$

$$
+\left[\mathrm{ET}_{\mathrm{obs}, t}-\mathrm{ET}_{\mathrm{sim}, t}\right] \mid
$$

Case V (SM, $\mathrm{ET}_{\mathrm{a}}$, and $\left.\mathrm{LAI}\right)$ :

$$
\begin{aligned}
\text { Objective Function }= & \frac{I}{N} \sum_{t=1}^{N} \mid 0.333\left[\mathrm{SM}_{\mathrm{obs}, t}-\mathrm{SM}_{\mathrm{sim}, t}\right] \\
& +0.333\left[\mathrm{ET}_{\mathrm{obs}, t}-\mathrm{ET}_{\mathrm{sim}, t}\right] \\
& +0.33\left[\mathrm{LAI}_{\mathrm{obs}, t}-\mathrm{LAI}_{\mathrm{sim}, t}\right] \mid
\end{aligned}
$$

Case VI (SM and $\left.\mathrm{ET}_{\mathrm{a}}\right)$ :

Objective Function $=\frac{I}{N} \sum_{t=1}^{N} \mid 0.5\left[\mathrm{SM}_{\mathrm{obs}, t}-\mathrm{SM}_{\mathrm{sim}, t}\right]$

$$
+\left[\mathrm{ET}_{\mathrm{obs}, t}-\mathrm{ET}_{\mathrm{sim}, t}\right]
$$

Case VII (SM and LAI):

$$
\begin{aligned}
\text { Objective Function }= & \frac{I}{N} \sum_{t=1}^{N} \mid 0.5\left[\mathrm{SM}_{\mathrm{obs}, t}-\mathrm{SM}_{\mathrm{sim}, t}\right] \\
& +\left[\mathrm{LAI}_{\mathrm{obs}, t}-\mathrm{LAI}_{\mathrm{sim}, t}\right] \mid
\end{aligned}
$$

where sim is the simulated data, obs is the observed data, and $t$ corresponds to time.

All simulations were run under several bottom boundary conditions (e.g., varying depths to groundwater and a free draining column at varying initial soil profile pressure head) to account for the sensitivity of the Mualem-van Genuchten parameters under different modeling conditions.

\subsection{Analysis}

The performance of the model was evaluated using Root Mean Square Error (RMSE) (Eq. (14)), Pearson Correlation Coefficient $(R)$ (Eq. (15)) and Mean Bias Error (MBE) (Eq. (16)). Lower RMSE indicates better performance of the model. Higher correlation shows higher correspondence between modeled and observed data however this does not reflect bias or scale of error. MBE provides a measure of the actual deviation between the predicted and measured values. The ideal value of MBE should be zero.

RMSE $=\sqrt{\frac{\sum_{i=1}^{n}\left(\theta_{\text {sim }, i}-\theta_{\mathrm{obs}, i}\right)^{2}}{n}}$

$R=\frac{\sum_{i=1}^{n}\left(\theta_{\mathrm{sim}, i}-\overline{\theta_{\mathrm{sim}}}\right)\left(\theta_{\mathrm{obs}, i}-\overline{\theta_{\mathrm{obs}}}\right)}{\sqrt{\sum_{i=1}^{n}\left(\theta_{\mathrm{sim}, i}-\overline{\theta_{\mathrm{sim}}}\right)^{2} \sum_{i=1}^{n}\left(\theta_{\mathrm{obs}, i}-\overline{\theta_{\mathrm{obs}}}\right)^{2}}}$

$\mathrm{MBE}=\frac{1}{n} \sum_{t=1}^{n}\left(\theta_{\text {sim }, t}-\theta_{\mathrm{obs}, t}\right)$

where $\theta_{\text {sim }}$ : simulated data; $\theta_{\text {obs }}$ : observed data; $\overline{\theta_{\text {sim, obs }}}$ : average of simulated or observed data; $n$ : the number of data.

Since $\mathrm{ET}_{\mathrm{a}}$-Bowen measurements appeared to be always larger than satellite $\mathrm{ET}_{\mathrm{a}}$ estimates, the inverse modeling performance was 
Table 3

Soil hydraulic parameters derived from difference search criteria.

\begin{tabular}{|c|c|c|c|c|c|c|c|}
\hline & $\mathrm{ET}_{\mathrm{a}}$ & LAI & SM & $\mathrm{ET}_{\mathrm{a}}+\mathrm{LAI}$ & $\mathrm{SM}+\mathrm{ET}_{\mathrm{a}}$ & $\mathrm{SM}+\mathrm{LAI}$ & $\mathrm{ET}_{\mathrm{a}}+\mathrm{LAI}+\mathrm{SM}$ \\
\hline \multicolumn{8}{|l|}{$3 \mathrm{~cm}$} \\
\hline$\theta_{r}$ & 0.08 & 0.08 & 0.09 & 0.06 & 0.03 & 0.08 & 0.10 \\
\hline$\theta_{s}$ & 0.57 & 0.39 & 0.39 & 0.47 & 0.39 & 0.39 & 0.42 \\
\hline$K_{\mathrm{s}}$ & 45.22 & 53.75 & 29.17 & 21.69 & 3.10 & 18.21 & 17.79 \\
\hline$\alpha_{\mathrm{dry}}$ & 0.03 & 0.02 & 0.03 & 0.03 & 0.03 & 0.03 & 0.03 \\
\hline$n$ & 1.48 & 1.56 & 1.23 & 1.54 & 1.32 & 1.23 & 1.23 \\
\hline \multicolumn{8}{|l|}{$12 \mathrm{~cm}$} \\
\hline$\theta_{r}$ & 0.15 & 0.10 & 0.15 & 0.08 & 0.16 & 0.13 & 0.11 \\
\hline$\theta_{s}$ & 0.45 & 0.52 & 0.54 & 0.51 & 0.52 & 0.53 & 0.52 \\
\hline$K_{\mathrm{s}}$ & 38.54 & 10.84 & 11.79 & 35.48 & 38.27 & 12.63 & 11.21 \\
\hline$\alpha_{\text {dry }}$ & 0.01 & 0.02 & 0.01 & 0.01 & 0.02 & 0.02 & 0.01 \\
\hline$n$ & 1.25 & 1.40 & 1.30 & 1.23 & 1.21 & 1.40 & 1.28 \\
\hline \multicolumn{8}{|l|}{$28 \mathrm{~cm}$} \\
\hline$\theta_{r}$ & 0.08 & 0.10 & 0.16 & 0.15 & 0.16 & 0.14 & 0.16 \\
\hline$\theta_{s}$ & 0.41 & 0.38 & 0.39 & 0.39 & 0.39 & 0.38 & 0.39 \\
\hline$K_{\mathrm{s}}$ & 42.54 & 4.26 & 45.38 & 3.10 & 44.49 & 16.32 & 43.49 \\
\hline$\alpha_{\text {dry }}$ & 0.01 & 0.02 & 0.02 & 0.01 & 0.03 & 0.03 & 0.02 \\
\hline$n$ & 1.32 & 1.20 & 1.40 & 1.34 & 1.49 & 1.36 & 1.52 \\
\hline \multicolumn{8}{|l|}{$60 \mathrm{~cm}$} \\
\hline$\theta_{r}$ & 0.10 & 0.12 & 0.16 & 0.10 & 0.10 & 0.09 & 0.13 \\
\hline$\theta_{s}$ & 0.54 & 0.47 & 0.60 & 0.52 & 0.60 & 0.57 & 0.58 \\
\hline$K_{\mathrm{s}}$ & 20.48 & 8.00 & 11.00 & 26.48 & 3.47 & 4.05 & 5.00 \\
\hline$\alpha_{\text {dry }}$ & 0.01 & 0.03 & 0.01 & 0.03 & 0.01 & 0.01 & 0.01 \\
\hline$n$ & 1.45 & 1.42 & 1.22 & 1.53 & 1.21 & 1.21 & 1.23 \\
\hline
\end{tabular}

Note: $\alpha\left(\mathrm{cm}^{-1}\right) ; n(-) ; \theta_{\text {sat }}\left(\mathrm{cm}^{3} \mathrm{~cm}^{-3}\right) ; \theta_{\text {res }}\left(\mathrm{cm}^{3} \mathrm{~cm}^{-3}\right) ; K_{\mathrm{sat}}\left(\mathrm{cm} \mathrm{d}^{-1}\right)$. ET $\mathrm{a}$, LAI and $\mathrm{ET}_{\mathrm{a}}+\mathrm{LAI}$ are excerpt from Charoenhirunyingyos et al. (2010).

only evaluated using field soil moisture and LAI-field measurements.

\section{Results and discussions}

3.1. Comparison of observed and simulated variables in the inverse modeling: single criterion

The results showed that using LAI as conditioning data in the inverse problem, SWAP-GA was able to match the calibrated LAI from satellite with high accuracy $(R=0.96)$ and low RMSE (Fig. 4) suggesting that derived soil hydraulic parameters have influenced the evolution of the canopy development along the growing season. In other words, LAI is sensitive to the soil hydraulic parameters. The strong correlation also suggests that the crop canopy parameters used in the model have been suitable for the rice variety planted in the field. But did LAI-derived soil hydraulic parameters able to simulate soil moisture accurately?

Correspondingly, the simulated $\mathrm{ET}_{\mathrm{a}}$ from the inverse model showed a strong correlation with $\mathrm{ET}_{\mathrm{a}}$ from SEBAL $(R=0.72)$ and a low RMSE $=0.13$ (Fig. 5). Considering certain factors such as the limitation of optical RS data (cloud contamination) during the growing
Comparison between Simulated ETa and Sat_ETa in Trakan Phutphon (2007)

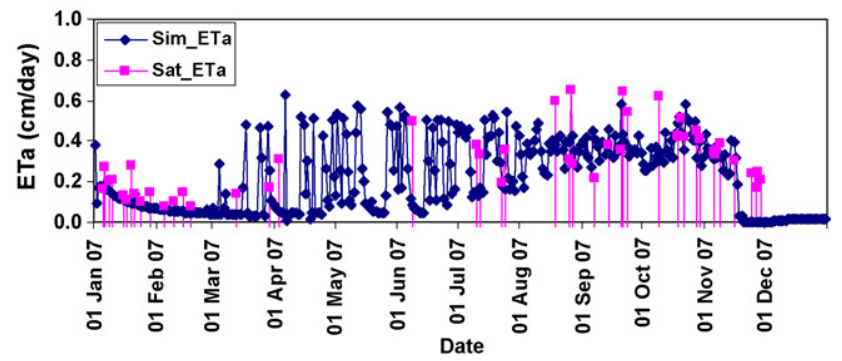

Fig. 5. Comparison between simulated $\mathrm{ET}_{\mathrm{a}}$ and satellite $\mathrm{ET}_{\mathrm{a}}$ in SWAP-GA model using $\mathrm{ET}_{\mathrm{a}}$ information (Charoenhirunyingyos et al., 2010).

season, and the scale of the satellite data, the correspondence between the SEBAL and simulated $\mathrm{ET}_{\mathrm{a}}$ by inverse modeling was remarkable.

Comparing the soil moisture from the site and the ones simulated by the inverse model when SM is used as conditioning data showed also a strong correlation $R=0.94$ and low $\mathrm{RMSE}=0.05$. Soil moisture is directly related to the soil hydraulic proper-

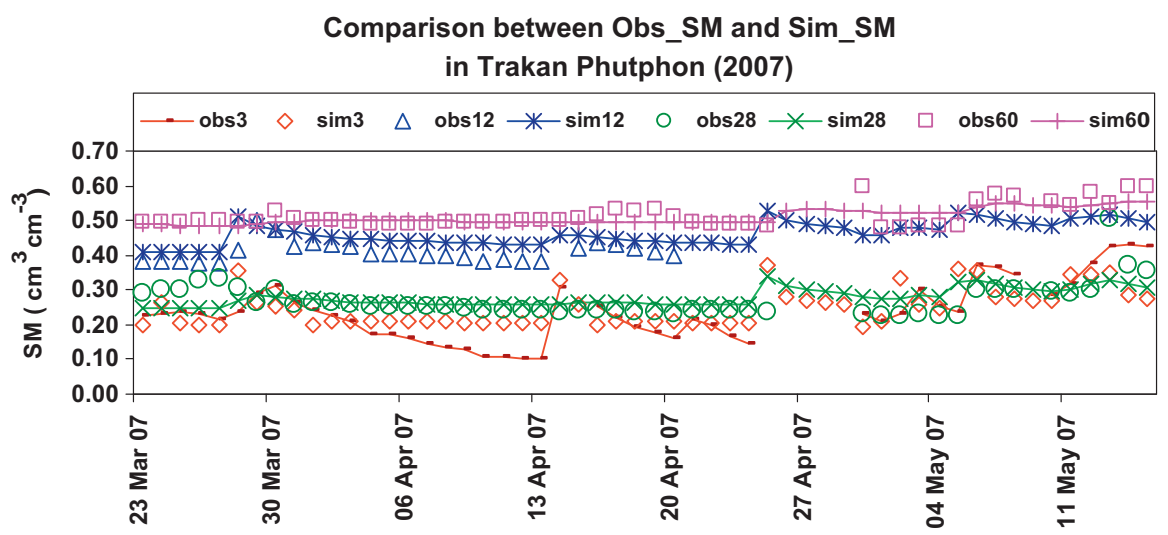

Fig. 6. Comparison between simulated SM and site SM in SWAP-GA model using soil moisture information. 

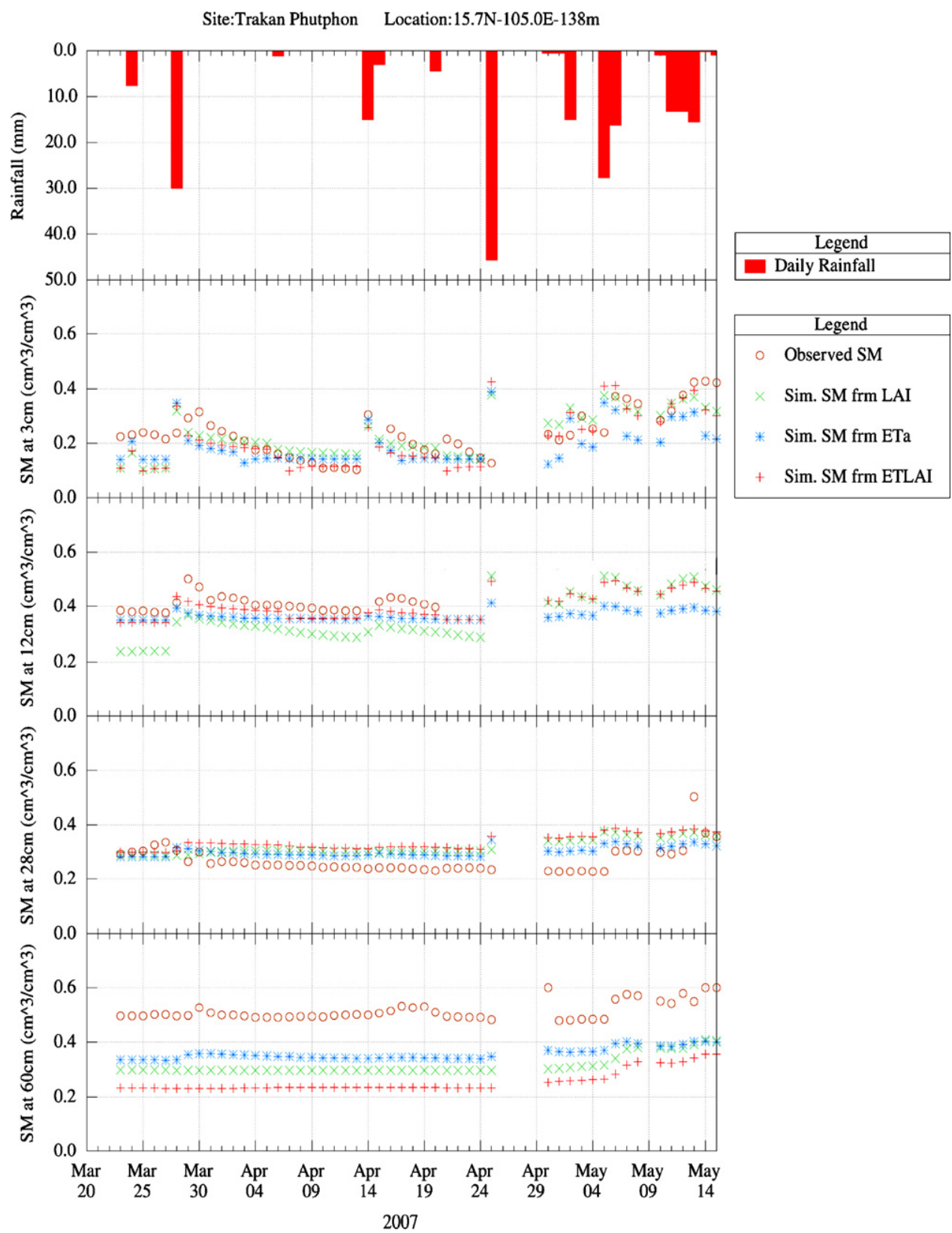

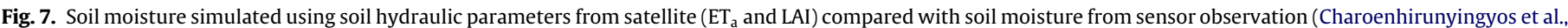
2010).

ties, thus it is expected that SM can inform the determination of the soil hydraulic parameters. Except for the slight mismatch at $3 \mathrm{~cm}$ depth, a better match between observed and simulated soil moisture (Fig. 6) could be obtained by the derived soil hydraulic parameters.

\subsection{Model inversion results}

Table 3 shows the soil hydraulic parameters derived from the single and multi-criteria inverse modeling experiments $\left(\mathrm{ET}_{\mathrm{a}}, \mathrm{LAI}\right.$, $\mathrm{SM}$ in combination or stand-alone). The following are the results of the simulated soil moisture when these parameters are used in forward modeling:

Soil hydraulic parameters estimated by LAI and/or $\mathrm{ET}_{\mathrm{a}}$ from satellite showed different outcomes in terms of soil moisture simulations. A comparison of the simulated and observed soil moisture showed a good match up to a depth of $28 \mathrm{~cm}$ (Fig. 7). Soil moisture at
$3 \mathrm{~cm}$ depth was better simulated using the soil hydraulic parameters derived from LAI than $\mathrm{ET}_{\mathrm{a}}$. While the best results at $12 \mathrm{~cm}$ depth was simulated using soil hydraulic parameters derived by the combination of $\mathrm{ET}_{\mathrm{a}}$ and LAI. At the deeper depths of 28 and $60 \mathrm{~cm}$, soil hydraulic parameters derived by $\mathrm{ET}_{\mathrm{a}}$ alone showed the better performance. Even though $\mathrm{ET}_{\mathrm{a}}$ derived parameters showed the better performance at the depth of $60 \mathrm{~cm}$, a large mean bias error was still observed. The results suggest that remotely sensed LAI and $\mathrm{ET}_{\mathrm{a}}$ derived soil hydraulic parameters may not be adequate for simulating soil moisture at deeper soil layers $(60 \mathrm{~cm})$. However, the extent of our experimentation (i.e., weights combination, forms of the search functions, hydro-climatic zones) was still limited hence further research is needed to ascertain this observation.

Fig. 8 shows the more improved simulated soil moisture (up to the depth of $60 \mathrm{~cm}$ ) using soil hydraulic parameters obtained from satellite data (LAI and $\mathrm{ET}_{\mathrm{a}}$ ) and in situ soil moisture (SM) compared to observations. The information contents from soil moisture 


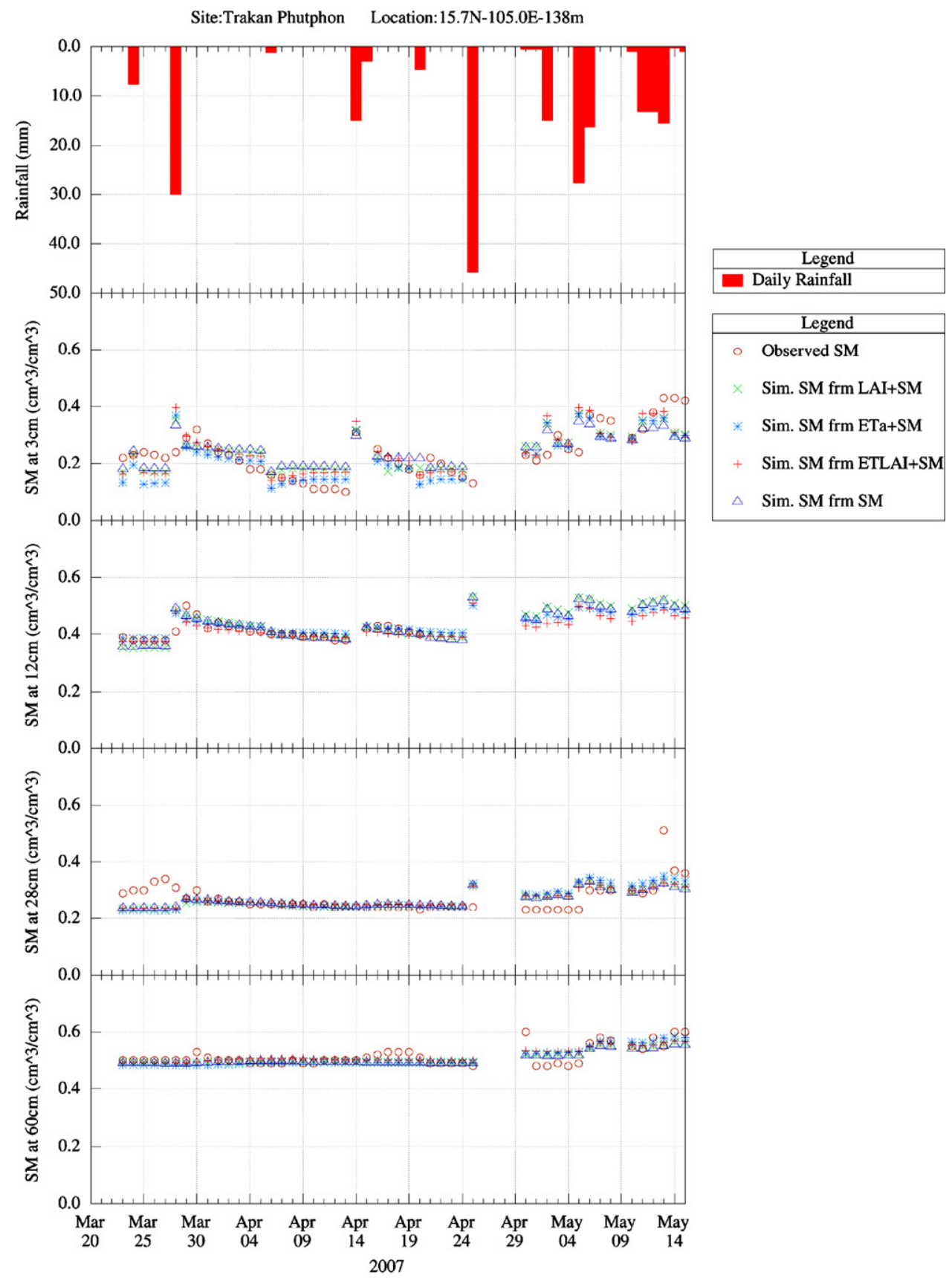

Fig. 8. Soil moisture simulated using soil hydraulic parameters from satellite plus soil moisture from site compared with soil moisture from sensor observation.

reduced most of the biases in the simulated soil moisture when combined with ET and LAI (respectively, and combined). Evidently, soil moisture alone can inform the estimation of soil hydraulic parameters.

\subsection{Evaluation of inverse model performance}

The performances of the inverse model are shown in Table 4. In Table 4, the RMSE, $\mathrm{R}$ and MBE values are those from soil moisture simulations under different search criteria. If soil moisture (SM) is not included in the search criteria that means the performance metric values are from the independent soil moisture observations, akin to validation. On the other hand, if soil moisture (as stand alone or in combination with $\mathrm{ET}_{\mathrm{a}}$ and $\mathrm{LAI}$ ) is included in the search criteria, it depicts more a calibration performance. Similarly, Table 5 shows the performance metrics for leaf area index simulations. If LAI is not included in the search criteria, the results serve as a crossvalidation of the inverse model performance in simulating LAI using the derived soil hydraulic parameters.

Soil moisture. At the $3 \mathrm{~cm}$ depth, the combination of satellitebased $\mathrm{ET}_{\mathrm{a}}$ and LAI produced the highest correlation $(R=0.78)$ for simulating soil moisture although its RMSE and MBE are second to the weakest (based on $\mathrm{ET}_{\mathrm{a}}$ alone). Adding soil moisture information from the field to satellite LAI or $\mathrm{ET}_{\mathrm{a}}$ improved the $R$ of simulated soil moisture and improved the under-estimation of soil moisture (positive MBE). As a single criterion, either LAI or, of course, soil moisture is the best for estimating soil hydraulic parameters at this shallow depth (Table 4).

At the $12 \mathrm{~cm}$ depth, LAI posed the best correlation $(R=0.87)$ in simulating soil moisture but had the worst RMSE and MBE. 
Table 4

Inverse modeling performance for simulating using soil moisture.

\begin{tabular}{|c|c|c|c|c|c|c|c|}
\hline & $\mathrm{ET}_{\mathrm{a}}$ & LAI & SM & $\mathrm{ET}_{\mathrm{a}}+\mathrm{LAI}$ & $\mathrm{SM}+\mathrm{ET}_{\mathrm{a}}$ & $\mathrm{SM}+\mathrm{LAI}$ & $\mathrm{SM}+\mathrm{ET}+\mathrm{LAI}$ \\
\hline \multicolumn{8}{|l|}{$3 \mathrm{~cm}$} \\
\hline RMSE & 0.08 & 0.06 & 0.06 & 0.07 & 0.06 & 0.06 & 0.06 \\
\hline$R$ & 0.64 & 0.73 & 0.74 & 0.78 & 0.75 & 0.76 & 0.75 \\
\hline MBE & -0.05 & -0.01 & 0.01 & -0.03 & -0.02 & 0.01 & 0.01 \\
\hline \multicolumn{8}{|l|}{$12 \mathrm{~cm}$} \\
\hline RMSE & 0.06 & 0.11 & 0.02 & 0.04 & 0.02 & 0.02 & 0.02 \\
\hline$R$ & 0.70 & 0.87 & 0.78 & 0.81 & 0.77 & 0.80 & 0.71 \\
\hline MBE & -0.05 & -0.10 & 0.00 & -0.04 & 0.01 & 0.00 & -0.01 \\
\hline \multicolumn{8}{|l|}{$28 \mathrm{~cm}$} \\
\hline RMSE & 0.05 & 0.07 & 0.05 & 0.08 & 0.05 & 0.05 & 0.05 \\
\hline$R$ & 0.43 & 0.35 & 0.40 & 0.34 & 0.42 & 0.41 & 0.42 \\
\hline MBE & 0.03 & 0.05 & 0.00 & 0.06 & 0.00 & 0.00 & 0.00 \\
\hline \multicolumn{8}{|l|}{$60 \mathrm{~cm}$} \\
\hline RMSE & 0.15 & 0.20 & 0.02 & 0.26 & 0.02 & 0.02 & 0.02 \\
\hline$R$ & 0.75 & 0.78 & 0.74 & 0.76 & 0.73 & 0.74 & 0.70 \\
\hline MBE & -0.15 & -0.20 & 0.00 & -0.26 & 0.00 & 0.00 & 0.00 \\
\hline
\end{tabular}

Note: RMSE $\left(\mathrm{cm}^{3} \mathrm{~cm}^{-3}\right), R(-), \operatorname{MBE}\left(\mathrm{cm}^{3} \mathrm{~cm}^{-3}\right) . \mathrm{ET}_{\mathrm{a}}, \mathrm{LAI}$ and $\mathrm{ET}_{\mathrm{a}}+\mathrm{LAI}$ are excerpt from Charoenhirunyingyos et al. (2010).

Table 5

Inverse modeling performance for simulating leaf area index.

\begin{tabular}{|c|c|c|c|c|c|c|c|}
\hline & LAI & $\mathrm{ET}_{\mathrm{a}}$ & SM & $\mathrm{ET}_{\mathrm{a}}+\mathrm{LAI}$ & $\mathrm{SM}+\mathrm{LAI}$ & $\mathrm{SM}+\mathrm{ET}_{\mathrm{a}}$ & $\mathrm{SM}+\mathrm{ET}_{\mathrm{a}}+\mathrm{LAI}$ \\
\hline RMSE & 0.35 & 0.30 & 0.35 & 0.33 & 0.31 & 0.31 & 0.31 \\
\hline$R$ & 0.94 & 0.95 & 0.94 & 0.94 & 0.95 & 0.95 & 0.95 \\
\hline MBE & -0.15 & -0.08 & -0.15 & -0.14 & -0.08 & -0.08 & -0.08 \\
\hline
\end{tabular}

The combination of $\mathrm{ET}_{\mathrm{a}}$ and LAI however yielded to a better performance (higher $R$ and moderately lower RMSE and MBE). As expected, introducing soil moisture information in combination with $\mathrm{ET}_{\mathrm{a}}$ and LAI improved significantly soil moisture RMSE and MBE but not necessarily the $R$-values.

At the $28 \mathrm{~cm}$ depth, $\mathrm{ET}_{\mathrm{a}}$ alone showed a better correlation $(R=0.43)$ among the search criteria used, with RMSE $=0.05$ and an $\mathrm{MBE}=0.03$. LAI derived soil hydraulic parameters posted a weaker performance in terms of simulating soil moisture. Even more, the worst performance came from the combination of $\mathrm{ET}_{\mathrm{a}}$ and LAI. Most of the mean bias errors disappeared when soil moisture information was applied in combination with $\mathrm{ET}_{\mathrm{a}}$ and LAI or by itself in the search criteria.

Lastly, using LAI alone gave the best correlation $(R=0.78)$ at the $60 \mathrm{~cm}$ depth, however its RMSE and MBE are larger than when using $\mathrm{ET}_{\mathrm{a}}$ alone (Table 4). Soil hydraulic parameters derived by $\mathrm{ET}_{\mathrm{a}}$ yielded an $R=0.75$, RMSE $=0.15$ and $\mathrm{MBE}=-0.15$. Note the underprediction of soil moisture in Fig. 8. Combining $\mathrm{ET}_{\mathrm{a}}$ and LAI did not improve the performance of simulating the soil moisture at the $60 \mathrm{~cm}$ depth. In fact, the RMSE and MBE deteriorated fairly. As established in the earlier results, adding soil moisture information to the search criteria ( $\mathrm{ET}_{\mathrm{a}}$ and/or $\mathrm{LAI}$ ) or being stand-alone removed most of the systematic errors in the simulation of soil moisture at this depth.

Leaf area index. Using field measurements of LAI (LAI meter by LICOR), the performance of the inverse model using single and multiple-criteria search functions was evaluated. Table 5 shows that using satellite LAI alone allowed the inverse model to simulate leaf area index at high accuracy $(R=0.94)$ but RMSE and MBE are around 0.35 and -0.15 , respectively. Interestingly, adding information from $\mathrm{ET}_{\mathrm{a}}$ and soil moisture to the search criteria slightly improved RMSE and MBE. This effect is more evident when field soil moisture was added with satellite LAI information in solving the inverse problem. However, using soil moisture information alone did not do any better that by using LAI information alone in the inverse modeling.

\section{Concluding remarks}

Inverse modeling is a promising technique for estimating soil hydraulic parameters for agro-hydrological modeling applications. In this study, we investigated the potential of using remotely sensed data, namely evapotranspiration $\left(\mathrm{ET}_{\mathrm{a}}\right)$ and leaf area index ( $\mathrm{LAI}$ ), for estimating soil hydraulic parameters of different soil layers in a rainfed rice field in Ubon Ratchathani Province, Thailand. We found that $\mathrm{ET}_{\mathrm{a}}$ and LAI are able to inform the inverse model to estimate soil hydraulic parameters that can simulate soil moisture reasonably well up to $28 \mathrm{~cm}$ depth. The information contents of satellite-derived LAI and $\mathrm{ET}_{\mathrm{a}}$, however, was not enough to infer soil hydraulic parameters that can simulate better at the deeper soil layer. Although the correlation between the inversely modeled soil moisture and observed is high, the mean bias is negatively large. This performance could be due to the non-sensitivity of the LAI and $\mathrm{ET}_{\mathrm{a}}$ to the deeper soil moisture; or, due to the lack of soil moisture variability on that layer as it is almost saturated throughout the growing season. LAI, however, posed the most remarkable performance in terms of informing the inverse model at the shallower depths (except for the $28 \mathrm{~cm}$ level, where $\mathrm{ET}_{\mathrm{a}}$ is more superior), and even at the deeper soil layer (in terms of correlation). Combining them could either improve or degrade the performance of the inverse model depending on the soil depths, and performance metric to consider (R, RMSE, MBE). Note however that our experiments were limited to just giving equal weights to $\mathrm{LAI}_{\text {and }} \mathrm{ET}_{\mathrm{a}}$ in the search function. Being able to quantify appropriate soil hydraulic properties for soil hydrological models using remote sensing would present a great opportunity to simulate soil moisture in larger, heterogeneous areas. But our results showed that remote sensed actual evapotranspiration and leaf area index can only inform shallower depths but mostly deeper than microwave measurements. Data that can inform the dynamics of deeper soil layers is therefore necessary. Here, we included in situ soil moisture in the multi-criteria function and was able to improve the simulation of soil moisture at the deeper soil layer. 


\section{Acknowledgements}

We thank the Thailand Research Fund (TRF) for supporting this research though a grant \#RDG4900006. We also thank our local collaborators, especially the officers of Agricultural Office of Muang Ubon Ratchathani District for their invaluable help during the conduct of the study. AVMI acknowledges the support from NOAA Cooperative Grant Agreement \#NA05OAR4311004.

\section{References}

Bastiaanssen, W.G.M., Meneti, M., Feddes, R.A., Holtslag, A.A.M., 1998. A remote sensing surface energy balance algorithm for land (SEBAL). Part 1 formulation. J. Hydrol. 212/213, 198-212.

Carroll, D.L., 1998. GA Fortran Driver version 1.7. Available online at: http://www.cuaerospace.com/carroll/ga.html (accessed 27.01.07).

Charoenhirunyingyos, S., Honda, K., Kamthonkiat, D., Ines, A.V.M., 2010. Soil hydraulic parameters estimated by satellite information through data assimilation. Int. J. Remote Sens., in press.

Enthekabi, D., Nakamura, H., Njoku, E., 1994. Solving the inverse problem for soil moisture and temperature profiles by sequential assimilation of multifrequency remotely sensed obersvations. IEEE T. Geosci. Remote Sens. 32 (2), 438-448.

Feddes, R.A., De Rooij, G.H., van Dam, J.C., Kabat, P., Droogers, P., 1993a. Estimation of regional effective soil hydraulic parameters by inverse modeling. In: Russo, D., Dagan, G. (Eds.), Water Flow and Solute Transport in Soils. Advanced Series in Agricultural Sciences. Berlin., pp. 211-233.

Feddes, R.A., Menenti, M., Kabat, P., Bastiaanssen, W.G.M., 1993b. Is large-scale inverse modeling of unsaturated flow with areal average evaporation and surface soil moisture as estimated by remote sensing feasible. J. Hydrol. 143, 125-152.

Feddes, R.A., Kowalik, P.J., Zaradny H., 1978. Simulation of field water use and crop yield. Simulation Monographs. Pudoc. Wageningen. 189pp.

Goldberg, D.E., 1989. Genetic Algorithms in Search and Optimization and Machine Learning. Addison-Wesley Publ. Co Inc., USA.

Gupta, H.V., Bastidas, L.A., Sorooshian, S., Shuttleworth, W.J., Yang, Z.L., 1999. Parameter estimation of a land surface scheme using multi-criteria methods. J. Geophys. Res. 104, 19491-19504.

Hogue, T.S., Bastidas, L., Gupta, H., Sorooshian, S., Mitchell, K., Emmerich, W., 2005 Evaluation and transferability of the Noah land surface model in semiarid environments. J. Hydrol. 6, 68-84.

Holland, J.H., 1975. Adaptation in Natural and Artificial Systems. MIT Press, Cambridge, MA.

Hong, S.-H., Hendrick, M.H., Jan, B.B., 2009. Up-scaling of SEBAL derived evapotranspiration maps from Landsat $(30 \mathrm{~m})$ to MODIS $(250 \mathrm{~m})$ scale. J. Hydrol. 370 $122-138$.

Ines, A.V.M., Honda, K., Gupta, D.A., Droogers, P., Clemente, R., 2006. Combining remote sensing-simulation modeling and genetic algorithm optimization to explore water management options in irrigated agriculture. Agric. Water Manage. 83 (3), 221-232, doi:10.1016/j.agwat.2005.12.006.
Ines, A.V.M., Mohanty, B.P., 2008. Near-surface soil moisture assimilation for quantifying effective soil hydraulic properties under different hydroclimatic conditions. Vadose Zone J. 7 (1), 39-52.

Ines, A.V.M., Droogers, P., 2002a. Inverse modeling in estimating soil hydraulic functions: a Genetic Algorithm approach. Hydrol. Earth Syst. Sci. 6 (1), 4965.

Ines, A.V.M., Droogers, P., 2002b. Inverse modeling to quantify irrigation system characteristics and operational management. Irrig. Drain. Syst. 16 (3), 233-252.

Jackson, T.J., Le Vine, D.M., Schmugge, T.J., Schiebe, F.R., 1995. Large area mapping of soil moisture using ESTAR passive microwave radiometer in Washita'92. Remote Sens. Env. 53, 27-37.

Jhorar, R.K., Bastiaanssen, W.G.M., Feddes, R.A., van Dam, J.C., 2002. Inversely estimating soil hydraulic functions using evaportranspiration fluxes. J. Hydrol. 258, $198-213$.

Jhorar, R.K., van Dam, J.C., Bastiaanssen, W.G.M., Feddes, R.A., 2004. Calibration of effective soil hydraulic parameters of heterogeneous soil profiles. J. Hydrol. 285, 233-247.

Liu, Y., Gupta, H.V., Sorooshian, S., Bastidas, L.A., Shuttleworth, W.J., 2005. Constraining land surface and atmospheric parameters of a locally coupled model using observational data. J. Hydrometeorol. 6, 156-172.

Mass, E.V., Hoffman, G.J., 1977. Crop salt tolerance: current assessment. J. Irrig. Drain. Div. ASCE 103, 115-134.

Mualem, Y., 1976. A new model for predicting the hydraulic conductivity of unsaturated porous media. Water Resour. Res. 12, 513-522.

Mutiga, J.K., Su, Z., Woldai, T., 2010. Using satellite remote sensing to assess evapotranspiration: Case study of the upperEwaso Ng'iro North Basin, Kenya. Int. J. Appl. Earth Observ. Geoinform., S100-S108, doi:10.1016/j.jag.2009.09.012.

Njoku, Eni, G., Jackson, T.L., Lakshmi, V., Chan, T., Nghiem, S.V., 2003. Soil Moisture Retrieval from AMSR-E. IEEE T. Geosci. Remote Sens. 41, 215-229.

Olioso, A., Inoue, Y., Ortega-Farias, S., Demarty, J., Wigneron, J.-P., Braud, I., Jacob, F., Lecharpentier, P., Ottlé, C., Calvet, J.-C., Brisson, N., 2005. Future directions for advanced evapotranspiration modeling: assimilation of remote sensing data into crop simulation models and SVAT models. Irrig. Drain. Syst. (19), 377-412.

Ragab, R., 1995. Towards a continuous operational system to estimate the root-zone soil moisture from intermittent remotely sensed surface. J. Hydrol. 173, 1-25.

Srivastava, H.S., Patel, P., Manchanda, M.L., Adiga, S., 2003. Use of multi-incidence angle Radarsat-1 SAR data to incorporate the effect of surface roughness in soil moisture estimation. IEEE T. Geosci. Remote 41, 1638-1640.

Supit, I., Hoyer, A.A., Van Diepen, C.A.(Eds.), 1994. System description of the WOFOST [6.0] crop simulation model implemented in the CGMS Vol. 1: Theory and algorithms. EUR Publication 15956, Agricultural Series, Luxemburg. 146p.

van Dam J.C. 2000. Field-scale water flow and solute transport. SWAP model concepts, parameter estimation and case studies. Doctoral Thesis, Wageningen University, Netherlands.

van Genuchten, M.Th., 1980. A closed-form equation for pre-dicting the hydraulic conductivity of unsaturated soils. Soil Sci. Soc. Am. J. 44, 892-898.

Walker, J.P., Willgoose, G.R., Kalma, J.D., 2001a. One-dimensional soil moisture profile retrieval by assimilation of near-surface measurements: a simplified soil moisture model and field application. J. Hydrometeorol. 2, 356-373.

Walker, J.P., Willgoose, G.R., Kalma, J.D., 2001b. One-dimensional soil moisture profile retrieval by assimilation of near-surface observations: a comparison of retrieval algorithms. Adv. Water Resour. 24, 631-650. 